\title{
CORRESPONDENCE.
}

\section{ATMOSPHERIC ROTARY MOVEMENTS OF SMALL EXTENT.}

The Editor, The Aëronautical Journal.

DeAR SIR,-About twenty years ago I witnessed a phenomenon similar to a "dust devil" in a newly-cut hayfield in Sussex. It was a very sunny afternoon, and I saw two or three spirals, rising perhaps twenty feet.

Yours faithfully,

C. DENDY MARSHALL.

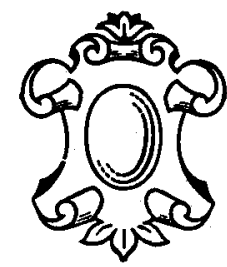

